\title{
Motor and sensory nerve conduction velocity in the baboon: normal values and changes during acrylamide neuropathy
}

\author{
A. P. HOPKINS AND R. W. GILLIATT \\ From the Institute of Neurology, Queen Square, London
}

SUMMARY Nerve conduction velocity and the amplitude of nerve and muscle action potentials have been measured in the median and anterior tibial nerves of normal adult and infant baboons. The effect of altered temperature on velocity has also been investigated. Seven adult baboons were intoxicated with acrylamide. In animals given $10-15 \mathrm{mg} / \mathrm{kg} / \mathrm{day}$, the gradual development of a peripheral neuropathy was accompanied by a decline in the amplitude of both muscle and nerve action potentials. There was also a gradual fall in conduction velocity. In some cases maximal motor velocity in the median nerve fell by as much as $34 \%$, and in the anterior tibial nerve by as much as $49 \%$, the largest falls being seen in animals showing the greatest reductions in response amplitude. Histological studies, reported elsewhere, have shown that the main pathological change in our animals was a degeneration of the peripheral nerves, with little demyelination. Fibre diameter histograms indicated that large fibres were particularly severely affected, and it seems likely that the reduced maximal conduction velocities were due to this selective loss of large-diameter fibres.

McLeod and Wray (1967) reported measurements of conduction velocity in the median and ulnar nerves of lightly anaesthetized baboons. The present study extends these observations to the anterior tibial nerve in the leg, and to purely sensory fibres in a digital branch of the median nerve. We also report changes in nerve conduction velocity and in the amplitude of muscle and nerve action potentials during the neuropathy induced by acrylamide $\left(\mathrm{CH}_{2}=\mathrm{CH} \mathrm{CONH}\right)_{2}$, a substance shown to produce peripheral nerve damage in man (Garland and Patterson, 1967; Fullerton, 1969) and in the rat (Fullerton and Barnes, 1966).

A description of the clinical illness produced by acrylamide in the baboon and of the histological changes in the peripheral nerves has been reported elsewhere (Hopkins, 1968, 1971).

\section{METHODS}

Observations on healthy baboons were made on 14 Papio anubis weighing 7.5 to $13.6 \mathrm{~kg}$ and on seven Papio hamadryas weighing 9.4 to $15.4 \mathrm{~kg}$. The age of the animals was not known, but nine of the $P$. anubis and five of the $P$. hamadryas were female and showed the changes of oestrus, which begins at about 4 years. Three infant baboons weighing 2.5 to $3.3 \mathrm{~kg}$ were also studied; on the basis of their weight and dentition these were believed to be between 9 and 15 months old. Large animals were caged singly, allowed 1 1. of water a day, and fed on a pellet diet (MRC $41 \mathrm{~B})$, with added fruit. Monthly injections of cyanocobalamin 1,000 $\mu \mathrm{g}$ (Glaxo Laboratories) were given to avoid the changes in the peripheral nerves described by Oxnard and Smith (1966) in captive $M$. rhesus.

Acrylamide in a dose of 10,15 , or $20 \mathrm{mg} / \mathrm{kg}$ was administered to seven large baboons as a $10 \%$ solution in water. Details of the dosage schedules are given by Hopkins (1968, 1971).

Light anaesthesia for the estimation of nerve conduction velocity was produced by intramuscular phencyclidine, $2 \mathrm{mg} / \mathrm{kg}$ (Sernylan: Parke, Davis and Co.), and promazine $1 \mathrm{mg} / \mathrm{kg}$ (Sparine: John Wyeth), followed by intravenous pentobarbitone $3 \mathrm{mg} / \mathrm{kg}$ (Nembutal: Abbot Laboratories).

The electrophysiological techniques were generally similar to those described by McLeod and Wray (1967). Examinations were carried out in a warm room maintained above $23^{\circ} \mathrm{C}$, and the animals were covered with a layer of cotton-wool to avoid heat loss during the anaesthesia. The limb under study was also covered except during manipulation of the electrodes. With these 
precautions a rectal temperature of $38^{\circ}$ to $39^{\circ} \mathrm{C}$ was easily maintained for long periods. Intramuscular temperature was checked with a thermistor in the flexor muscles of the forearm during measurements on conduction in the arm, and ranged from $35.0^{\circ}$ to $38.9^{\circ} \mathrm{C}$. During measurements of conduction in the digital nerves, the temperature of a fold of skin near the thenar eminence was checked, and ranged from $35.0^{\circ}$ to $39.0^{\circ} \mathrm{C}$. Intramuscular temperature in the anterior tibial compartment of the leg ranged from $35.0^{\circ}$ to $39.0^{\circ} \mathrm{C}$.

Conduction velocity was measured in the median and anterior tibial nerves of the left limbs. All pathological specimens were taken from the right limbs; this ensured that any histological changes which were found were due to the acrylamide and not to the previous insertion of needle electrodes. Stimulating and recording electrodes were 20 gauge stainless steel needles which were placed subcutaneously. For the measurement of motor conduction velocity the stimulating cathodes were placed close to the nerve, above the elbow and at the wrist for the median nerve, and at the head of the fibula and at the ankle for the anterior tibial nerve. Muscle action potentials were recorded through needle electrodes placed over the abductor pollicis brevis and extensor digitorum brevis muscles respectively. The active electrode was placed over the muscle belly, and a remote electrode over a tendon at the base of a digit, the position of the active electrode being adjusted to give the largest negative deflection. Electrode positions used for the motor velocity studies are shown in Fig. 1a and d.

Ascending nerve action potentials were recorded from the median nerve through needle electrodes placed above the elbow, with stimulation at the wrist (Fig. 1b); in the case of the anterior tibial nerve, the recording electrodes were placed at the knee, with the stimulating cathode at the ankle (Fig. 1e). For stimulation of the digital fibres in the index finger, the cathode was placed at the base of the finger, with the anode distally; the ascending volley was recorded through electrodes placed $4 \mathrm{~cm}$ apart over the median nerve at the wrist (Fig. 1c).

The conduction distance between wrist and elbow was usually approximately $25 \mathrm{~cm}$, between knee and ankle $15 \mathrm{~cm}$, and between the index finger and wrist $9 \mathrm{~cm}$.

The stimulus was a condenser discharge with a timeconstant of 20,50 , or $100 \mu \mathrm{sec}$ delivered once per second through a $1: 1$ isolating transformer. The output impedance was less than $1 \mathrm{k} \Omega$. The stimulus voltage was continuously variable up to $300 \mathrm{~V}$. The recorded potentials were amplified by an $\mathrm{R}-\mathrm{C}$ coupled amplifier and displayed on the upper beam of an oscilloscope, a crystal-controlled time-scale being displayed on the lower beam. Photographic records were made on $35 \mathrm{~mm}$ film and, when recording nerve action potentials, 25 superimposed traces of each potential were photographed.

FIG. 1. Placement of electrodes for the measurement of maximal conduction velocity and response amplitude in the median and anterior tibial nerves. Arrangements for recording muscle action potentials shown in a and $\mathrm{d}$, mixed nerve action potentials in $\mathrm{b}$ and $\mathrm{e}$, sensory nerve action potentials in c. S: stimulating cathode, A: anode, $\mathrm{R}$ : recording electrode.
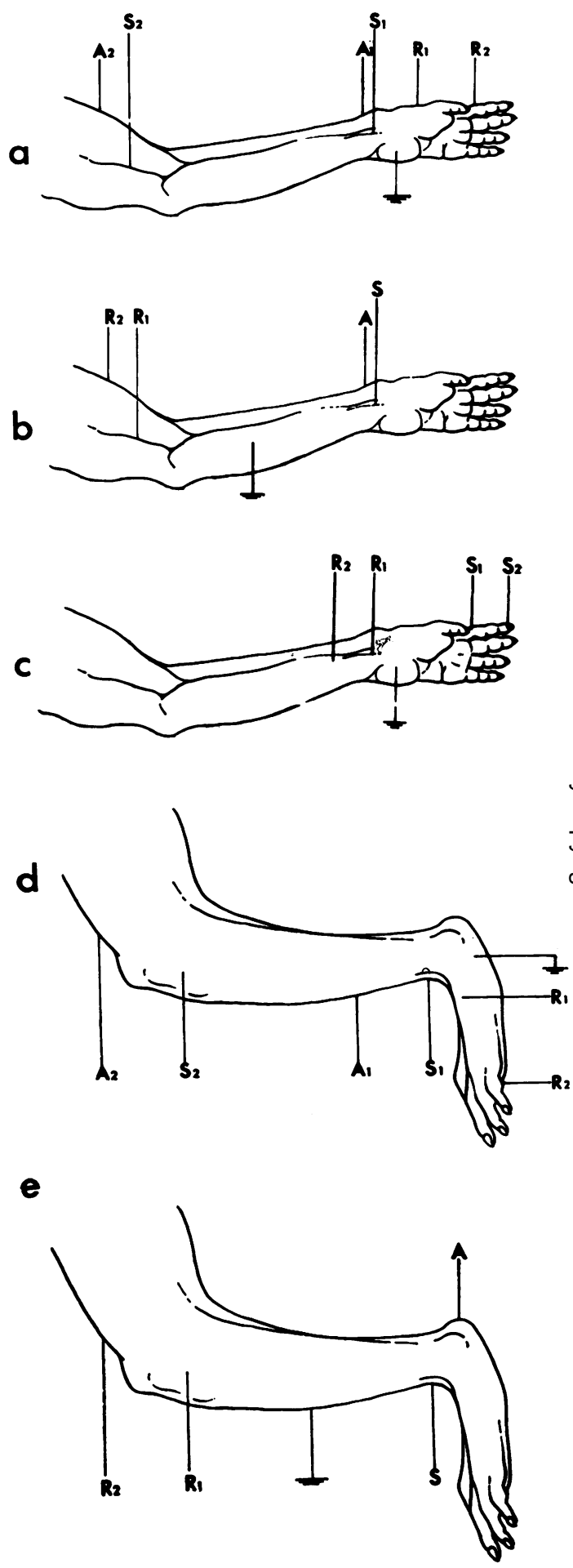
When placing stimulating electrodes, care was taken to reduce as far as possible the spread of stimulus to adjacent nerves. When stimulating motor fibres in the median nerve, it was not always possible to elicit a maximal muscle action potential from abductor pollicis brevis without some spread of current to the ulnar nerve. Even when it was impossible to eliminate this completely, we were able to satisfy ourselves that it had a negligible effect on the amplitude of the response recorded from abductor pollicis brevis. To check this, the ulnar nerve was stimulated directly with weak shocks, and it was then clear that, although there was excitation of ulnarsupplied hand muscles, the active recording electrode over abductor pollicis brevis muscle showed only a small deflection. It was also established that, when recording ascending nerve action potentials from the median nerve, slight spread of stimulus to the ulnar nerve at the wrist did not affect the amplitude of the nerve action potential recorded from the median nerve at the elbow.

It was, however, important to limit stimulus strength in order to avoid spread of current along the nerve with resultant reduction in latency. For this reason stimulus intensity was not increased by more than 10 or $20^{\circ}$ 。 above that necessary to produce a maximal response.

When recording ascending nerve action potentials from the anterior tibial nerve, it was necessary to stimulate with near-threshold as well as with supramaximal shocks. The reason for this is illustrated by the normal tracings in Fig. 2. In Fig. 2a a potential is shown in response to a stimulus with an intensity which was above threshold for some afferent fibres, but below threshold for all motor fibres. The latency to the foot of the negative deflection was $2.45 \mathrm{msec}$. When the stimulus intensity was progressively increased (Fig. 2b and c) the initial positive wave grew and the original negative deflection was seen as a hump on the positive wave. The latency to the foot of the main negative deflection was then $2 \cdot 70 \mathrm{msec}$.

From records such as those shown in Fig. 2, it seems that in the anterior tibial nerve there is a small group of low-threshold afferent fibres which might be overlooked unless near-threshold as well as supramaximal stimuli are used.

\section{RESULTS}

\section{NORMAL ANIMALS}

A. EFFECT OF TEMPERATURE In two animals body temperature was lowered over a period of several hours by means of icepacks, fans, and repeated doses of phencyclidine. The rectal temperature fell to $30^{\circ}-31^{\circ} \mathrm{C}$, and limb temperature to $29^{\circ} \mathrm{C}$. Nerve conduction velocity was estimated during cooling in the median and anterior tibial nerves of baboon 26, and in the anterior tibial nerve of baboon 9 .

Results are shown in Fig. 3 and Table 1, from which it can be seen that there was a linear fall in velocity as cooling proceeded. Regression lines have been calculated for each nerve, and are shown in Fig. 3. Gradients range from $1.74 \mathrm{~m} / \mathrm{sec} / \mathrm{C}$ for
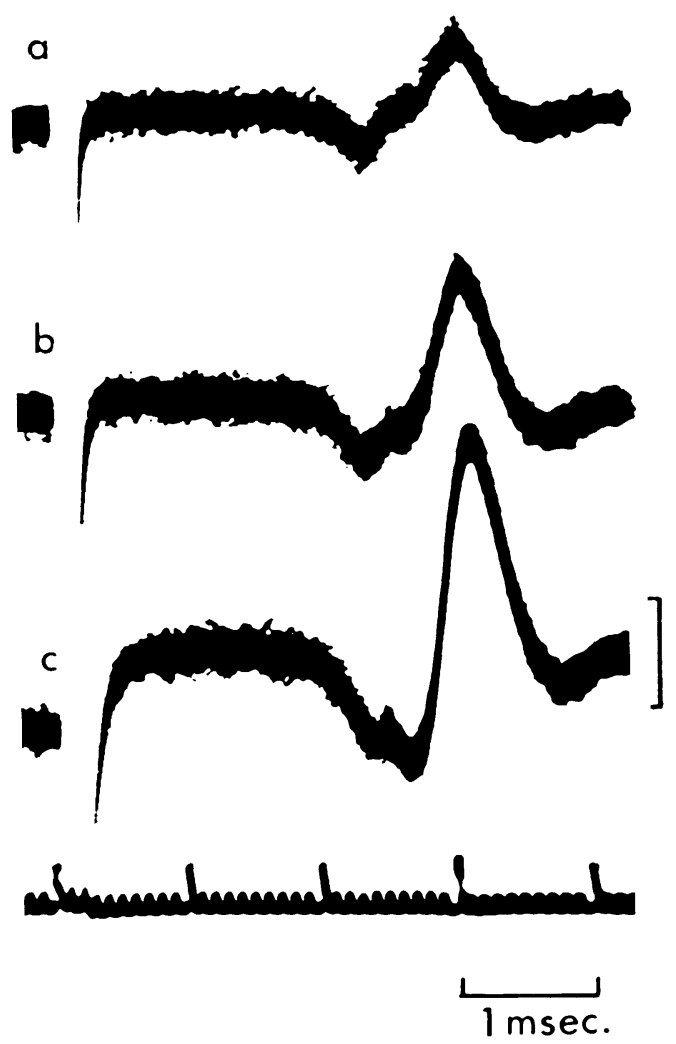

FIG. 2. Ascending action potentials recorded from the normal anterior tibial nerve to show the effect of increasing stimulus intensity. Twenty-five consecutive traces superimposed in each case. Calibration: $10 \mu \mathrm{V}$. For further explanation see text.

the median sensory nerve action potential up to $3.42 \mathrm{~m} / \mathrm{sec} /{ }^{\circ} \mathrm{C}$ for the anterior tibial ascending nerve action potential. The $\mathrm{Q}_{10}\left(27^{\circ}\right.$ to $\left.37^{\circ} \mathrm{C}\right)$, assuming linearity is maintained below the lowest temperature at $29 \cdot 1^{\circ} \mathrm{C}$, varies between 1.37 and 1.64 with a mean of 1.49 which is in approximate agreement with the figures of Gasser (1931), Paintal (1965), and others.

From the data in Table 1, conduction velocities in other animals have been corrected for deviations of temperature from $37^{\circ} \mathrm{C}$.

B. RANGE OF NORMAL. VARIATION The values for conduction velocity in the median and anterior tibial nerves before and after adjustment to $37^{\circ} \mathrm{C}$ are shown in Table 2 . These are calculated from observations on 21 baboons weighing from $7 \cdot 8$ to $15.0 \mathrm{~kg}$. As found by McLeod and Wray (1967), the velocity of the fastest afferent fibres in the median nerve between the wrist and elbow was substantially 


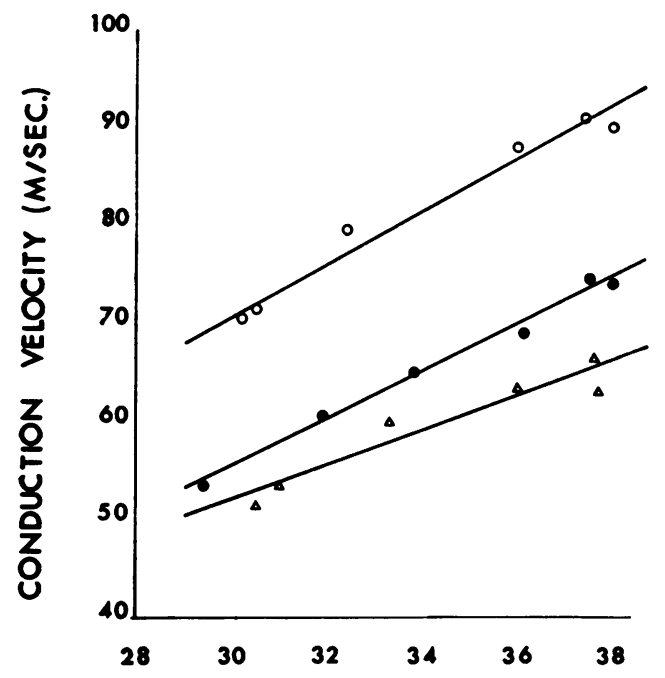

TEMPERATURE $\left({ }^{\circ} \mathrm{C}\right)$

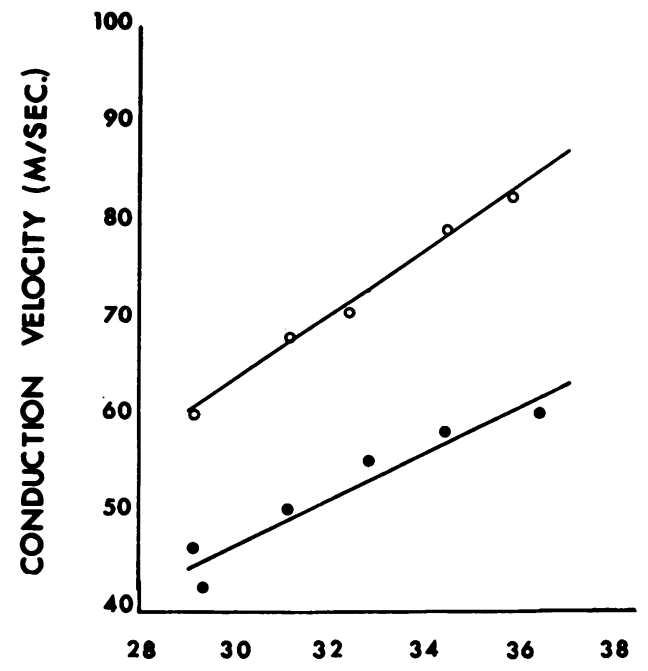

TEMPERATURE $(\circ \mathrm{C})$

FIG. 3. Baboon 23. The effect of temperature on maximal conduction velocity. Results for the median nerve shown above, and for the anterior tibial nerve below. $=$ values for motor velocity; $\bigcirc=$ velocity of ascending nerve action potentials; $\triangle=$ velocity of sensory nerve action potentials.

greater than that of the motor fibres to abductor pollicis brevis, the mean values in our animals being $86.3 \mathrm{~m} / \mathrm{sec}$ and $72.6 \mathrm{~m} / \mathrm{sec}$ for the afferent and efferent fibres respectively. A similar difference was present in the anterior tibial nerve between the knee
TABLE 1

EFFECT OF COOLING ON CONDUCTION VELOCITY

\begin{tabular}{|c|c|c|c|c|}
\hline Nerve & Baboon & $\begin{array}{c}\text { Observations } \\
\text { (no.) }\end{array}$ & $\begin{array}{c}\text { Gradient } \\
\left(\mathrm{m} / \mathrm{sec} /^{\circ} \mathrm{C}\right)\end{array}$ & $Q_{10} \frac{\overline{\bar{Q}}}{\square}$ \\
\hline Median motor & 26 & 6 & $2 \cdot 41$ & $1.50 \stackrel{2}{2}$ \\
\hline Median ascending & 26 & 6 & $2 \cdot 61$ & $1.41 \stackrel{\rho}{\supset}$ \\
\hline Median sensory & 26 & 6 & $1 \cdot 74$ & $1 \cdot 37 \overline{\mathrm{Q}}$ \\
\hline Anterior tibial motor & 26 & 6 & $2 \cdot 32$ & 1.58 盯 \\
\hline Anterior tibial motor & 9 & 7 & $2 \cdot 22$ & $1.47 \leqslant$ \\
\hline Anterior tibial ascending & 26 & 5 & $3 \cdot 42$ & $1.64 \rightrightarrows$ \\
\hline
\end{tabular}

and ankle, the mean values for afferent and efferent $\frac{\overline{\bar{c}}}{\overline{\frac{\rho}{\sigma}}}$ velocity being $77.6 \mathrm{~m} / \mathrm{sec}$ and $64.0 \mathrm{~m} / \mathrm{sec}$ respectively. $\overparen{\Phi}$ The mean value for the ascending action potential recorded at the wrist when the index finger was stimulated was $67 \cdot 8 \mathrm{~m} / \mathrm{sec}$.

Amplitudes of the evoked muscle action potentials $\overrightarrow{\vec{A}}$ and of nerve action potentials are also shown in $\omega_{\sigma}$ Table 2, from which it can be seen that the range of amplitude was greater than the range of velocity. In order to establish whether this variation re- $\omega$ presented differences between animals or differences $;$ due to the technique itself, 28 measurements wege $A$ repeated in nine animals. The findings are shown $\overrightarrow{\mathrm{D}} \overrightarrow{\mathrm{G}}$ Table 3. When the results were corrected for tent? perature, the conduction velocity at the seconf examination was within $\pm 10 \%$ of the initial figure $?$ in 27 out of 28 pairs. However, the variation amplitude of muscle action potentials was less tho $\pm 20 \%$ in only nine out of 13 repeated experiment C. EFFECT OF AGE ON CONDUCTION VELOCITY Table 4 shows the data for the three infant baboons. It can be seen that 12 of the 15 values obtained for velocity fell within the normal range for large animals, although 11 of the 15 were below the adult mean. $\frac{\circ}{D}$ The amplitudes of nerve and muscle action potentials $\varrho$ fell within the normal range for large animals in $\overrightarrow{0}$ 13 cases. The two exceptions were values for as- 3 cending nerve action potentials in the median nerve; in both cases action potential amplitude was larger than in the adult animals.

BABOONS INTOXICATED WITH ACRYLAMIDE five large female and two large male $P$. hamadryas. $ᄋ$ Details of the clinical illness and of the pathological changes have been reported elsewhere (Hopkins, 음 $1968,1971)$. In summary, the animals developed a progressive polyneuropathy affecting both motor and sensory fibres. One animal was given $20 \overline{\mathrm{N}}$ $\mathrm{mg} / \mathrm{kg} / \mathrm{day}$ and developed such severe generalized $\sigma$ weakness within four weeks that administration was $N$ stopped. A lower dose (10 or $15 \mathrm{mg} / \mathrm{kg} /$ day) was $\underset{\mathrm{C}}{ }$ given to the remaining six animals. These animals 
TABLE 2

MAXIMAL CONDUCTION VELOCITY AND AMPLITUDE OF MUSCLE AND NERVE ACTION POTENTIALS (NAPS) IN LARGE BABOONS*

\begin{tabular}{|c|c|c|c|c|c|c|c|c|c|c|}
\hline & \multirow{3}{*}{$\begin{array}{l}\text { Observations } \\
\text { (no.) }\end{array}$} & \multicolumn{6}{|c|}{ Conduction velocity $(\mathrm{m} / \mathrm{sec})$} & \multicolumn{3}{|c|}{ Amplitude $\dagger$} \\
\hline & & \multicolumn{3}{|c|}{ Original temperature } & \multicolumn{3}{|c|}{ Adjusted to $37^{\circ} \mathrm{C}$} & \multirow[b]{2}{*}{ Range } & \multirow[b]{2}{*}{ Mean } & \multirow[b]{2}{*}{$S D$} \\
\hline & & Range & Mean & $S D$ & Range & Mean & $S D$ & & & \\
\hline $\begin{array}{l}\text { Median motor to APB } \\
\text { Median ascending NAP } \\
\text { Median sensory NAP } \\
\text { Anterior tibial motor to EDB } \\
\text { Anterior tibial ascending NAP }\end{array}$ & $\begin{array}{l}28 \\
27 \\
26 \\
27 \\
22\end{array}$ & $\begin{array}{l}62 \cdot 2-84 \cdot 6 \\
73 \cdot 2-100 \cdot 0 \\
58 \cdot 5-79 \cdot 6 \\
55 \cdot 8-69 \cdot 0 \\
56 \cdot 5-90 \cdot 5\end{array}$ & $\begin{array}{l}72 \cdot 8 \\
86 \cdot 2 \\
67 \cdot 6 \\
63 \cdot 6 \\
77 \cdot 0\end{array}$ & $\begin{array}{l}5 \cdot 2 \\
6 \cdot 2 \\
6 \cdot 4 \\
3 \cdot 4 \\
7 \cdot 0\end{array}$ & $\begin{array}{l}66 \cdot 2-82 \cdot 9 \\
75 \cdot 8-98 \cdot 5 \\
58 \cdot 4-80 \cdot 6 \\
58 \cdot 2-67 \cdot 8 \\
58 \cdot 6-90 \cdot 2\end{array}$ & $\begin{array}{l}72 \cdot 6 \\
86 \cdot 3 \\
67 \cdot 8 \\
64 \cdot 0 \\
77 \cdot 6\end{array}$ & $\begin{array}{l}4 \cdot 1 \\
5 \cdot 8 \\
6 \cdot 2 \\
2 \cdot 6 \\
6 \cdot 9\end{array}$ & $\begin{array}{r}8 \cdot 1-20 \cdot 5 \\
7 \cdot 3-50 \cdot 5 \\
13 \cdot 3-44 \cdot 5 \\
4 \cdot 9-20 \cdot 9 \\
5 \cdot 9-45 \cdot 5\end{array}$ & $\begin{array}{l}15 \cdot 6 \mathrm{mV} \\
26 \cdot 7 \mu \mathrm{V} \\
25 \cdot 2 \mu \mathrm{V} \\
11 \cdot 2 \mathrm{mV} \\
19 \cdot 4 \mu \mathrm{V}\end{array}$ & $\begin{array}{r}3 \cdot 0 \\
10 \cdot 1 \\
9 \cdot 8 \\
3 \cdot 9 \\
9 \cdot 8\end{array}$ \\
\hline
\end{tabular}

*Weight: $7 \cdot 8$ to $15 \cdot 0 \mathrm{~kg}$.

† Muscle action potential amplitude is that recorded with nerve stimulation at wrist and ankle. For comparison with stimulation at elbow and knee, see Table 6 .

TABLE 3

RESULTS OBTAINED BY REPEATED EXAMINATION OF SAME ANIMAL: SECOND OBSERVATION AS PERCENTAGE OF FIRST

\begin{tabular}{|c|c|c|c|c|}
\hline & $\begin{array}{l}\text { Nerves } \\
\text { examined } \\
(\text { no. })\end{array}$ & Range & Mean & $S D$ \\
\hline $\begin{array}{l}\text { Motor conduction velocity } \\
\text { uncorrected for temp: } \\
\text { corrected to } 37^{\circ} \mathrm{C}: \\
\text { Velocity of mixed ascending }\end{array}$ & 13 & $\begin{array}{l}88-117 \\
92-108\end{array}$ & $\begin{array}{l}102.4 \\
100 \cdot 7\end{array}$ & $\begin{array}{l}8.9 \\
5.2\end{array}$ \\
\hline $\begin{array}{l}\text { nerve action potentials } \\
\text { uncorrected for temp: } \\
\text { corrected to } 37^{\circ} \mathrm{C} \\
\text { Velocity of median sensory }\end{array}$ & 9 & $\begin{array}{l}87-139 \\
90-133\end{array}$ & $\begin{array}{l}105 \cdot 7 \\
105 \cdot 1\end{array}$ & $\begin{array}{l}14.9 \\
11.9\end{array}$ \\
\hline $\begin{array}{l}\text { nerve action potentials } \\
\text { uncorrected for temp: } \\
\text { corrected for temp: }\end{array}$ & 6 & $\begin{array}{l}98-108 \\
91-105\end{array}$ & $\begin{array}{l}99 \cdot 5 \\
98.5\end{array}$ & $\begin{array}{l}4.9 \\
4.6\end{array}$ \\
\hline \multirow{3}{*}{$\begin{array}{l}\text { Amplitude of } \\
\text { Muscle action potentials } \\
\text { Mixed ascending nerve ac- } \\
\text { tion potentials } \\
\text { Median sensory nerve ac- } \\
\text { tion potentials }\end{array}$} & 13 & $81-187$ & 119.5 & $30 \cdot 3$ \\
\hline & 9 & $47-180$ & $106 \cdot 4$ & $44 \cdot 6$ \\
\hline & 6 & $96-123$ & $108 \cdot 0$ & $13 \cdot 7$ \\
\hline
\end{tabular}

developed an illness of slower evolution, ataxia and weakness of the limbs appearing after eight to 12 weeks, and increasing slowly so that by the end of 15 to 25 weeks there was severe weakness of the limbs and usually of the facial and bulbar muscles. One animal (B16) was moribund after 27 weeks and was killed, but in the remaining five baboons acrylamide was stopped when they became so weak that it was difficult to feed them. The total period of intoxication varied from 13 to 27 weeks. Two animals were killed two to three weeks after stopping acrylamide and three were allowed to recover for between 11 and 25 months before being killed.

2. CHANGES IN NERVE CONDUCTION DURING ACRYLAMIDE The gradual development of weakness of the limbs in the baboons receiving 10 or $15 \mathrm{mg} / \mathrm{kg} / \mathrm{day}$ was accompanied by a progressive reduction in the amplitude of muscle and nerve action potentials. Conduction was studied in the median and anterior tibial nerves at intervals of two to four weeks in all the animals during the administration of toxin. Recordings were made at longer intervals during recovery. A total of 306 velocities was recorded. Examples of the records obtained are shown in Fig. 4, which displays the series of action potentials recorded from the extensor digitorum brevis muscle of baboon 15, and the median sensory nerve action potentials from the same animal. During intoxication there was a progressive decline in the amplitude of

TABLE 4

MAXIMAL CONDUCTION VELOCITY AND AMPLITUDE OF MUSCLE AND NERVE ACTION POTENTIALS (NAPS) IN THREE INFANT BABOONS

\begin{tabular}{|c|c|c|c|c|c|c|}
\hline \multirow[b]{2}{*}{ Number of animal and weight $(k g)$} & \multicolumn{3}{|c|}{$\begin{array}{l}\text { Conduction velocity }(\mathrm{m} / \mathrm{sec}) \\
\left.\text { (adjusted to } 37^{\circ} \mathrm{C}\right)\end{array}$} & \multicolumn{3}{|c|}{ Amplitude $\dagger$} \\
\hline & $I(2 \cdot 8)$ & $I I(2 \cdot 5)$ & $I I I(3 \cdot 3)$ & $I(2 \cdot 8)$ & $I I(2 \cdot 5)$ & III (3·3) \\
\hline $\begin{array}{l}\text { Median motor to APB } \\
\text { Median ascending NAP } \\
\text { Median sensory NAP } \\
\text { Anterior tibial to EDB } \\
\text { Anterior tibial ascending NAP }\end{array}$ & $\begin{array}{l}72 \cdot 3 \\
88 \cdot 2 \\
69 \cdot 1 \\
65 \cdot 2 \\
78 \cdot 7\end{array}$ & $\begin{array}{l}65 \cdot 7 \\
81 \cdot 0 \\
59 \cdot 7 \\
57 \cdot 0 \\
65 \cdot 4\end{array}$ & $\begin{array}{l}69 \cdot 1 \\
82 \cdot 4 \\
51 \cdot 4^{*} \\
54 \cdot 6^{*} \\
71 \cdot 6\end{array}$ & $\begin{array}{r}18 \cdot 4 \\
20 \cdot 0 \\
23 \cdot 4 \\
6 \cdot 4 \\
18 \cdot 3\end{array}$ & $\begin{array}{r}12 \cdot 8 \\
66 \cdot 4^{*} \\
30 \cdot 0 \\
8 \cdot 3 \\
18 \cdot 9\end{array}$ & $\begin{array}{r}8 \cdot 8 \mathrm{mV} \\
51 \cdot 2 \mu \mathrm{\mu} \\
37 \cdot 8 \mu \mathrm{V} \\
8 \cdot 8 \mathrm{mV} \\
21 \cdot 1 \mu \mathrm{V}\end{array}$ \\
\hline
\end{tabular}

*Indicates values falling outside the normal range (cf. Table 2).

† Muscle action potential amplitude is that obtained by distal stimulation, as in Table 2. 
DAY
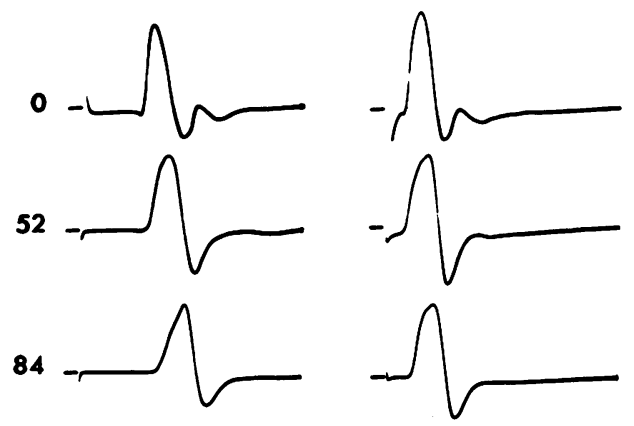

101

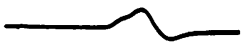

112

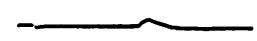

127

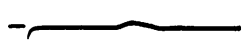

157

189

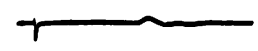

234

284

364

459

570

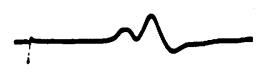

711

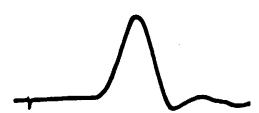

828
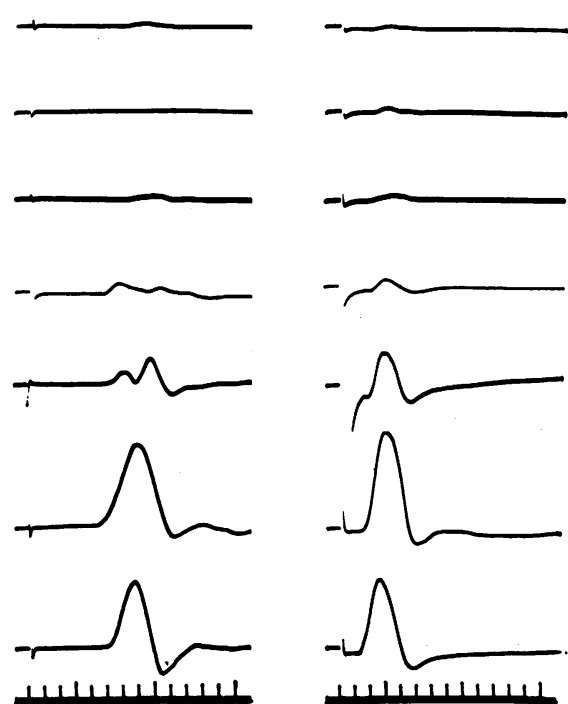
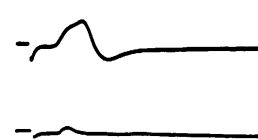

$-$
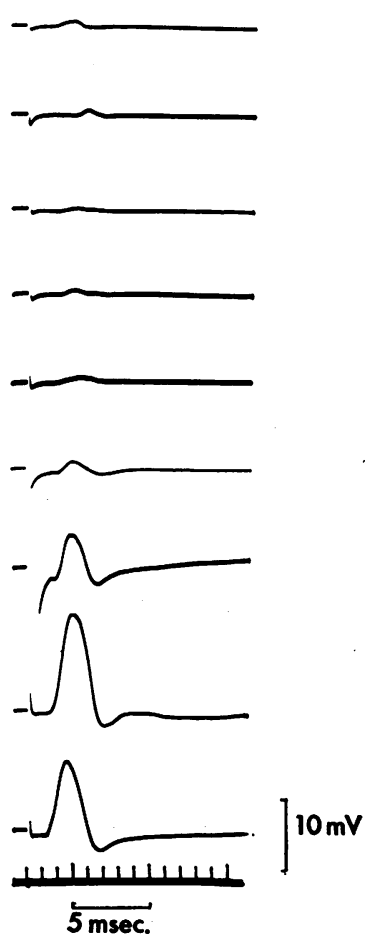
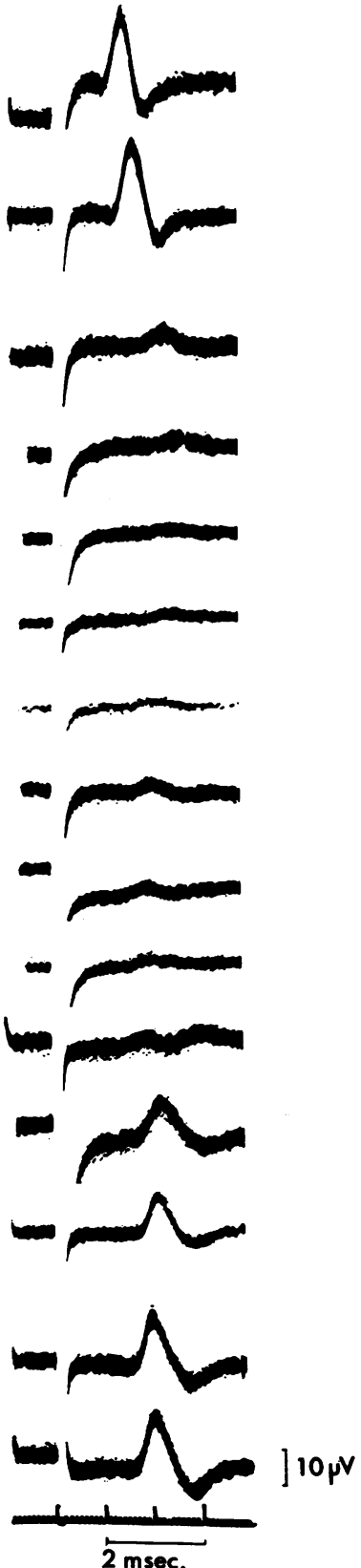

FIG. 4. Serial records from baboon 15; acrylamide administered for 94 days. On the left, muscle action potentials recorded from extensor digitorum brevis; on the right, sensory nerve action potentials recorded from the median nerve. 
the muscle and nerve action potentials with an increase in latency. Acrylamide was stopped on day 94 . It can be seen that further deterioration occurred after this time, and that recovery of action potential amplitude was not apparent until day 459.

The changes in the six animals on 10 or $15 \mathrm{mg} / \mathrm{kg}$ of acrylamide per day are summarized in Table 5 in which the velocities and amplitudes recorded at the end of the period of intoxication are expressed as percentages of the initial figure. Because the velocities and amplitudes continued to diminish for several weeks after stopping acrylamide, the figures shown are those obtained on the day nearest to three weeks after the toxin was stopped. At this time no action potentials could be recorded from the extensor digitorum brevis muscle or anterior tibial nerve of $\mathrm{B} 19$, or from the median nerve of B23. In these cases the velocity obtained at the previous recording is shown. It can be seen that as a result of the administration of acrylamide the mean figure for maximal motor velocity fell to $78 \%$ of the initial value in the median nerve and to $62 \%$ of the initial value in the anterior tibial nerve. The percentage reduction in muscle action potential amplitude was also greater in the foot than in the hand. These results support the clinical impression that the disease was usually more severe in the lower than in the upper limbs.

Reviewing the data for nerve action potentials shown in Table 5, it may be noted that the percentage decrease in both velocity and amplitude was greater for sensory than for motor conduction in the median nerve, figures for the mixed ascending action potential (which would include antidromic impulses in motor fibres) being intermediate between the two.

In the lower limb a similar comparison between motor and sensory conduction cannot be made, as no purely sensory nerve was examined, but it is interesting that in the anterior tibial nerve, the initial low-threshold component of the ascending action potential was sometimes abolished before the main deflection of the action potential was greatly reduced in size. This point could not, however, be established satisfactorily in all the animals owing to the small size of the early component.

From Table 5 it can be seen that marked reductions in maximal motor velocity usually occurred in those animals in which response amplitude was also greatly reduced. Figure 5 shows maximal motor velocity during the course of the illness plotted against response amplitude, both values being expressed as percentages of those obtained before acrylamide. Results for the median nerve are shown above, and for the anterior tibial nerve below. It can be seen that, in both nerves, velocity and response amplitude tend to decrease together during the course of the illness. The calculated regression lines for conduction velocity $(\mathrm{y})$ and response amplitude (x) are:

For the median nerve $y=65.6+0.322 x$ correlation coefficient $0.69, \mathrm{P}<0.001$

For the anterior tibial nerve $y=54 \cdot 1+0 \cdot 368 x$ correlation coefficient $0.69, \mathrm{P}<0.001$

On this basis one would expect maximal motor velocity in the median nerve to fall to $65.6 \%$ of normal (SE 7.9) before the muscle response finally disappeared. The corresponding figure for the anterior tibial nerve is $54.1 \%$ (SE 10.4). The significance of these findings in relation to the histological changes is discussed in a later section.

During intoxication there was no evidence of progressive dispersion of the muscle action potential,

TABLE 5

MAXIMAL CONDUCTION VELOCITY AND RESPONSE AMPLITÚDE AFTER ACRYLAMIDE ADMINISTRATION

\begin{tabular}{|c|c|c|c|c|c|c|c|c|c|c|}
\hline \multirow[b]{4}{*}{ Baboon } & \multicolumn{10}{|c|}{ Per cent initial value } \\
\hline & \multicolumn{6}{|c|}{ Median nerve } & \multicolumn{4}{|c|}{ Anterior tibial nerve } \\
\hline & \multicolumn{2}{|c|}{ Motor } & \multicolumn{2}{|c|}{ Ascending } & \multicolumn{2}{|c|}{ Sensory } & \multicolumn{2}{|c|}{ Motor } & \multicolumn{2}{|c|}{ Ascending } \\
\hline & $v$ & $a$ & $v$ & $a$ & $v$ & $a$ & $v$ & $a$ & $v$ & $a$ \\
\hline 15 & 66 & 27 & 60 & 11 & 58 & 4 & 51 & 6 & 65 & 12 \\
\hline 16 & 82 & 59 & 78 & 39 & 70 & 7 & 77 & 39 & 76 & 75 \\
\hline 17 & 66 & 45 & 70 & 17 & 76 & 8 & 67 & 53 & 68 & 15 \\
\hline 19 & 94 & 36 & 73 & 7 & 66 & 13 & *58 & 0 & *74 & 0 \\
\hline 23 & 74 & 13 & $* 78$ & 0 & $* 73$ & 0 & 51 & 8 & 60 & 18 \\
\hline 25 & 87 & 62 & 88 & 57 & 74 & 15 & 69 & 49 & 69 & 36 \\
\hline Mean & 78 & 40 & 75 & 22 & 70 & 8 & 62 & 26 & 69 & 26 \\
\hline
\end{tabular}

Conduction velocity $(v)$ and amplitude $(a)$ are expressed as percentages of the initial values before intoxication with acrylamide. The figures are those obtained at the recording on the day nearest to three weeks after stopping acrylamide. If no action potential could be recorded on this day then the velocity for the immediately preceding recording has been entered in the Table, and is indicated by an asterisk. Figures for muscle action potential amplitude are those obtained by distal stimulation, as in Table 2. 


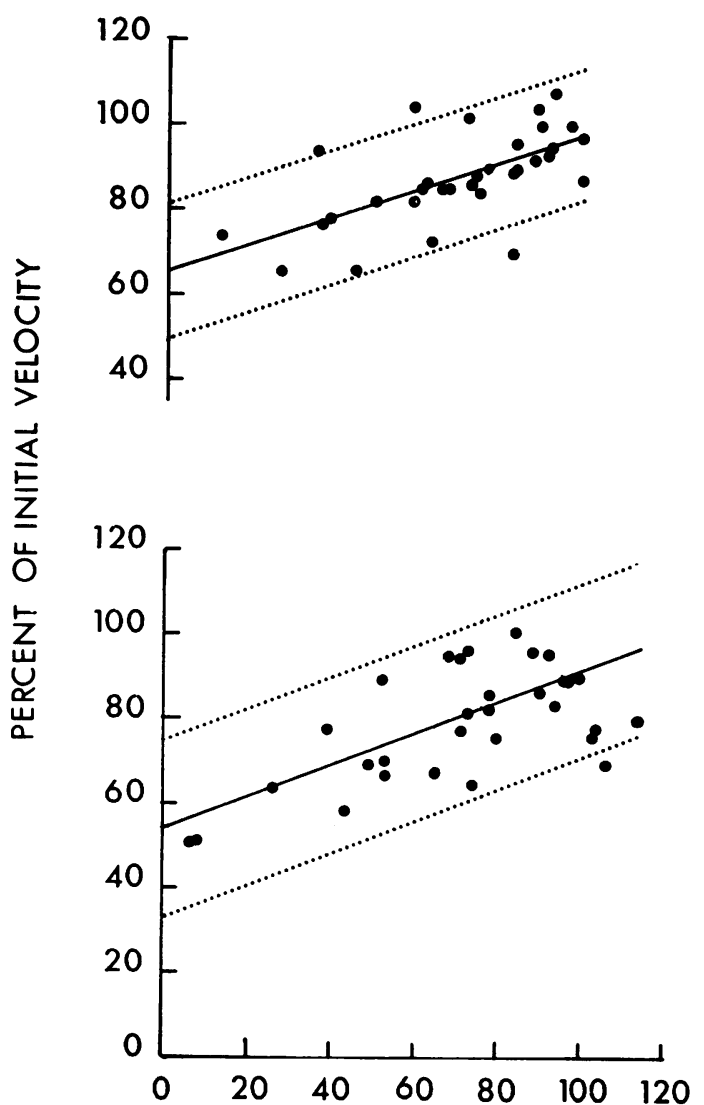

PERCENT OF INITIAL AMPLITUDE

FIG. 5. The amplitude of muscle action potentials plotted against conduction velocity during and immediately after the administration of acrylamide in six animals. Results, expressed as percentages of pre-acrylamide values, are shown for the median nerve above and for the anterior tibial nerve below. Calculated regression lines have been drawn, $\pm 2 S E$.

the response to proximal stimulation being similar in amplitude and duration to that evoked by distal stimulation. The ratio:

amplitude of muscle action potential on proximal stimulation/amplitude of muscle action potential on distal stimulation $\times 100$

has been calculated and results before and three weeks after intoxication are given in Table 6 . It can be seen that there is no significant change in the ratio, although the mean amplitude of the response to distal stimulation fell to $40 \%$ of the initial value in the upper limb and to $26 \%$ in the lower limb
TABLE 6

AMPLITUDE OF MUSCLE RESPONSES TO PROXIMAL AND DISTAL STIMULATION: MEAN VALUES FOR SIX ANIMALS BEFORE AND AFTER ACRYLAMIDE

\begin{tabular}{|c|c|c|c|}
\hline \multicolumn{4}{|c|}{ Amplitude on proximal stimulation } \\
\hline \multicolumn{4}{|c|}{ Amplitude on distal stimulation } \\
\hline \multicolumn{2}{|c|}{ Median nerve } & \multicolumn{2}{|c|}{ Anterior tibial nerve } \\
\hline Before & After & Before & After \\
\hline $92 \cdot 5$ & 88.0 & $93 \cdot 7$ & $95 \cdot 0$ \\
\hline
\end{tabular}

(Table 5). There is thus no evidence of conduction block developing between the stimulating cathodes.

Changes in distal latency during intoxication are shown in Table 7. The results before and three weeks after intoxication show an increase of an $\vec{\circ}$ order which might be expected from the changes in $\overrightarrow{\vec{\omega}}$ velocity in the proximal parts of the same nerves. $\stackrel{\omega}{\sim}$ In no animal was there an increase in distal latency substantially greater than might be expected from? the proximal change in velocity.

3. CHANGES IN NERVE CONDUCTION AFTER STOPPINO ACRYLAMIDE As noted in a previous sectio electrophysiological deterioration sometimes co록 tinued for several weeks after stopping acrylamideFor example, in the case of baboon 15 (Fig. acrylamide was stopped on day 94 . The amplitude of the muscle action potential recorded from extensor digitorum brevis was $9.7 \mathrm{mV}$ on day $8 \bar{\Phi} \overrightarrow{\vec{\theta}}$ $3.6 \mathrm{mV}$ on day 101 , and only $0.8 \mathrm{mV}$ on day $11 \overrightarrow{2}$. The conduction velocity in the anterior tibial nerve was $50.0,40.6$, and $33.4 \mathrm{~m} / \mathrm{sec}$ on these three occasions. The amplitude of the ascending nerve action potential at the knee was 15,8 and $3 \mu \mathrm{V}$ on these occasions; it declined to approximately $1 \mu \mathrm{V} \stackrel{\circ}{\mathbb{D}}$ on day 127, and was absent on day 157 .

This late decline in conduction velocity and in the amplitude of muscle and nerve action potentials was also seen in B19, B23, and B25. It represents an interesting phenomenon and one which requires further study.

The time course of subsequent recovery is shown in Table $\mathbf{8}$ for the three animals which were allowed $\frac{5}{3}$

TABLE 7

DISTAL LATENCY BEFORE AND AFTER ACRYLAMIDE ADMINISTRATION: MEAN VALUES FOR SIX ANIMALS

\begin{tabular}{|c|c|c|c|}
\hline \multicolumn{4}{|c|}{ Distal latency in msec } \\
\hline \multicolumn{2}{|c|}{ Median nerve } & \multicolumn{2}{|c|}{ Anterior tibial nerve } \\
\hline Before & After & Before & After \\
\hline $1 \cdot 96$ & $2 \cdot 65$ & $1 \cdot 10$ & $1 \cdot 43$ \\
\hline
\end{tabular}


TABLE 8

VELOCITY ( $v$ ) AND AMPLITUDE ( $a$ ) OF MUSCLE AND NERVE ACTION POTENTIALS DURING RECOVERY, EXPRESSED AS PERCENTAGE OF INITIAL VALU'E

\begin{tabular}{|c|c|c|c|c|c|c|c|c|c|c|c|c|c|c|c|c|c|c|c|c|c|c|}
\hline \multirow[b]{3}{*}{$\begin{array}{l}\text { B15 } \\
\text { Median motor } \\
\text { Ant. tib. motor } \\
\text { Median sensory }\end{array}$} & \multicolumn{22}{|c|}{ Months after stopping acrylamide } \\
\hline & \multicolumn{2}{|c|}{$\frac{1}{4}$} & \multicolumn{2}{|c|}{3} & \multicolumn{2}{|r|}{$I$} & \multicolumn{2}{|c|}{3} & \multicolumn{2}{|c|}{4} & \multicolumn{2}{|c|}{6} & \multicolumn{2}{|r|}{9} & \multicolumn{2}{|c|}{12} & \multicolumn{2}{|c|}{16} & \multicolumn{2}{|r|}{21} & \multicolumn{2}{|r|}{24} \\
\hline & $\begin{array}{l}v \\
78 \\
63 \\
59\end{array}$ & $\begin{array}{r}a \\
39 \\
26 \\
7\end{array}$ & $\begin{array}{l}v \\
66 \\
51 \\
58\end{array}$ & $\begin{array}{r}a \\
27 \\
6 \\
4\end{array}$ & $\begin{array}{l}v \\
71 \\
56 \\
64\end{array}$ & $\begin{array}{r}a \\
48 \\
5 \\
4\end{array}$ & $\begin{array}{c}v \\
73 \\
64 \\
67\end{array}$ & $\begin{array}{r}a \\
52 \\
5 \\
12\end{array}$ & $\begin{array}{c}v \\
73 \\
57 \\
78\end{array}$ & $\begin{array}{r}a \\
50 \\
3 \\
12\end{array}$ & $\begin{array}{c}v \\
82 \\
71\end{array}$ & $\begin{array}{c}a \\
72 \\
-\quad 12\end{array}$ & $\begin{array}{l}v \\
85 \\
59 \\
81\end{array}$ & $\begin{array}{r}a \\
55 \\
5 \\
10\end{array}$ & $\begin{array}{l}v \\
93 \\
83 \\
83\end{array}$ & $\begin{array}{l}a \\
76 \\
10 \\
49\end{array}$ & $\begin{array}{l}v \\
91 \\
79 \\
74\end{array}$ & $\begin{array}{l}a \\
58 \\
43 \\
53\end{array}$ & $\begin{array}{l}v \\
96 \\
83 \\
70\end{array}$ & $\begin{array}{c}a \\
90 \\
94 \\
71\end{array}$ & $\begin{array}{l}v \\
94 \\
73 \\
70\end{array}$ & $\begin{array}{c}a \\
80 \\
77 \\
84\end{array}$ \\
\hline $\begin{array}{l}\text { B17 } \\
\text { Median motor } \\
\text { Ant. tib. motor } \\
\text { Median sensory }\end{array}$ & & & $\begin{array}{l}66 \\
67 \\
76\end{array}$ & $\begin{array}{r}45 \\
53 \\
8\end{array}$ & $\begin{array}{l}65 \\
64 \\
70\end{array}$ & $\begin{array}{r}75 \\
117 \\
7\end{array}$ & $\begin{array}{l}65 \\
71 \\
83\end{array}$ & $\begin{array}{r}72 \\
102 \\
5\end{array}$ & $\begin{array}{l}73 \\
74 \\
71\end{array}$ & $\begin{array}{r}92 \\
121 \\
3\end{array}$ & $\begin{array}{l}81 \\
88 \\
78\end{array}$ & $\begin{array}{r}102 \\
91 \\
4\end{array}$ & $\begin{array}{l}93 \\
96 \\
73\end{array}$ & $\begin{array}{r}86 \\
114 \\
7\end{array}$ & $\begin{array}{l}90 \\
86 \\
75\end{array}$ & $\begin{array}{r}100 \\
102 \\
25\end{array}$ & $\begin{array}{l}85 \\
94 \\
72\end{array}$ & $\begin{array}{r}90 \\
135 \\
37\end{array}$ & & & & \\
\hline
\end{tabular}

B23

$\begin{array}{lllllllll}\text { Median motor } & 71 & 13 & 62 & 18 & 70 & 38 & 88 & 39\end{array}$

$\begin{array}{lrrrrrrrr}\text { Ant. tib. motor } & 51 & 8 & 76 & 25 & 79 & 25 & 81 & 37\end{array}$

Median sensory

to survive for up to 24 months after stopping acrylamide. Baboon 15 was the most severely affected of the three. There was little change in the amplitude of the response recorded from extensor digitorum brevis until the end of the first year, when it was still only $10 \%$ of normal. The amplitude had increased to $80 \%$ of normal by the end of the second year. Velocity in the anterior tibial nerve remained between 50 and $60 \%$ of normal during the first nine months, after which it progressively increased to reach $80 \%$ of normal. Recovery in the median nerve was more rapid. Baboon 17 was a mildly affected animal, and some recovery in the amplitude of the muscle action potential was found within two months. Fewer observations are available for B23, but some recovery was apparent within three months. In all three animals the muscle action potentials were prolonged during recovery, this being more marked on proximal than on distal nerve stimulation, with a smaller response amplitude on proximal stimulation. Examples of these changes can be seen in Fig. 4.

In all three animals the amplitude of the median sensory nerve action potential recovered more slowly than that of the muscle response. In B23, there was no detectable recovery of sensory conduction in the six months during which the animal was followed, although motor conduction improved significantly during the same period.

4. ELECTROPHYSIOLOGICAL CHANGES IN B18 This animal had a larger daily dose of acrylamide than the others $(20 \mathrm{mg} / \mathrm{kg}$ as opposed to $10-15 \mathrm{mg} / \mathrm{kg})$ and developed a severe clinical illness after a latent period of only 18 days. After 29 days it was quadriplegic, and acrylamide was stopped. Rapid recovery occurred, the animal appearing clinically normal by the time it was killed on day 93. Nerve conduction was examined on days $31,38,52$, and 73 . In spite of severe clinical paralysis on day 31 , maximal velocity in all the nerves examined was within the normal range, and response amplitude was only slightly reduced (see appendix XII of Hopkins, 1968). This animal is of interest in showing normal motor nerve conduction at a time when it was clinically severely paralysed. It has been suggested elsewhere (Hopkins, 1971) that in this case some damage to the central nervous system had also occurred.

\section{DISCUSSION}

Our normal results for the median nerve are generally similar to those obtained by McLeod and Wray (1967). In both studies it has been shown that the median nerve at the wrist contains afferent fibres with a velocity substantially greater than that of the fastest motor fibres, the difference being of the order of $20 \%$. The afferent velocities obtained by McLeod and Wray were slightly higher than our own but the difference in the mean values of the two sets of observations is not statistically significant. McLeod and Wray's techniques might be expected to yield slightly higher velocities than the present work, since these authors placed a hot water bottle under the limb which was being studied, in order to maintain the temperature between $37^{\circ}$ and $39^{\circ} \mathrm{C}$. Their results were not subsequently adjusted to a standard limb temperature of $37^{\circ} \mathrm{C}$ as has been done in the present study.

A difference between the fastest efferent and afferent velocities was found by McLeod and Wray not only in the median but also in the ulnar nerve. In the present work a similar difference has been found to exist in the anterior tibial nerve. In this nerve a small deflection preceding the main negative spike of the ascending action potential can often be 
identified. The results of stimulation below motor threshold show that this early deflection is due to impulses in a group of low-threshold afferent fibres.

In the present study conduction velocity in digital afferent fibres was measured between the index finger and the wrist, and was found to be lower than that of motor fibres in the forearm. Recent experiments by Hern have shown that when digital afferent velocity is measured between the wrist and elbow, it is similar to that of the fastest motor fibres over the same distance (Hern, 1970). The slower velocity distal to the wrist is not due to a difference in temperature, and it presumably indicates branching or tapering of the nerve fibres in their distal parts. Independent anatomical evidence of fibre branching in the distal part of the median nerve has been obtained by Wray (1969).

Our findings in the three small baboons (assumed ages 9 to 15 months) are interesting, in that they suggest a more rapid maturation of peripheral nerves during infancy than occurs in man. According to Thomas and Lambert (1960) and Gamstorp (1963), conduction velocity in human peripheral nerves continues to increase rapidly between the ages of 1 and 3 years, whereas our own results suggest that most of this increase occurs within the first year of life in the baboon.

The changes in conduction velocity which we have found in baboons intoxicated by acrylamide can be interpreted in the light of the histological findings. The latter have been presented elsewhere (Hopkins, 1971) but a summary may be given here. Acrylamide produces degeneration of both axons and myelin, the changes following the pattern of a so-called 'dying-back' lesion, with maximal involvement of the peripheral parts of the fibres and less damage proximally. For example, the sciatic nerve and spinal roots were normal in animals with severe degeneration of the anterior tibial nerve in the foot.

If the characteristic pathological change is a degeneration commencing distally, how can one account for the decrease in maximal conduction velocity? The explanation would seem to be that the fastest-conducting fibres are affected first. There is anatomical evidence for this, since fibre diameter histograms from nerves taken at different stages of the clinical illness show a greater loss of large myelinated fibres than of small ones. To emphasize this point a histogram of the diameter of surviving fibres in the sural nerve of baboon 15 is shown in Fig. 6. The biopsy specimen was taken on day 141, after acrylamide had been stopped but while the animal was still severely paralysed; this was long before nerve and muscle action potentials showed evidence of regeneration (compare Fig. 4 from the same animal). In the absence of regeneration,

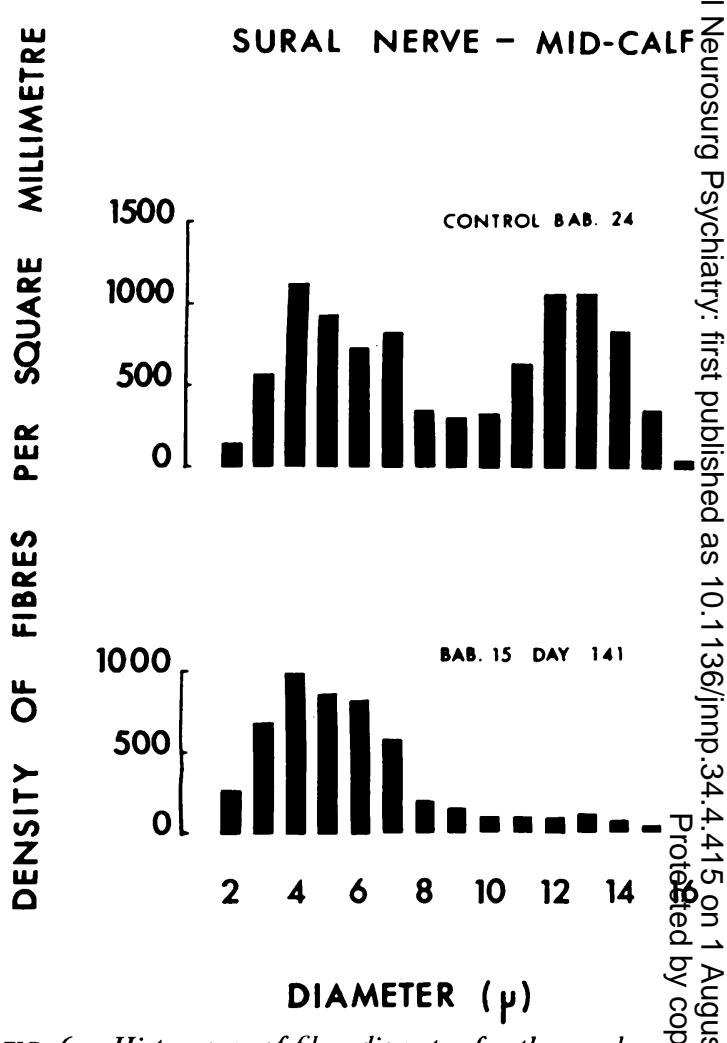

FIG. 6. Histograms of fibre diameter for the sural nexters of baboon 24 (control) and of baboon 15 (acrylan for 94 days).

appearances such as those shown in Fig. 6 may be assumed to indicate a selective effect of acrylamideo on large-diameter fibres. A similar selective effect̋ was postulated by Fullerton and Barnes (1966) too account for their results with acrylamide in the rat. $\overrightarrow{\vec{\theta}}$

Our electrophysiological findings also favour lossङ of the fastest-conducting fibres as the explanation? of the reduced conduction velocity. As shown ino Fig. 5, maximal motor velocity fell as the size of the muscle response diminished, the lowest velocities? being associated with the greatest reductions in:response amplitude. In the ascending anterior tibia 3 . nerve action potential, there was in some animals as small initial deflection which disappeared before the 3 main negative deflection of the action potential waso greatly reduced in size. This is additional evidence of selective large fibre loss.

In the anatomical studies there was evidence of some paranodal demyelination in addition to theo complete degeneration which affected the distalin parts of the fibres (Hopkins, 1971). However, it seems unlikely that paranodal demyelination con- 
tributed to the reduced conduction velocity for several reasons. In the first place, it affected only a small proportion of the fibres at any one level, and only a proportion of the nodes on any one fibre. In the second place, it seemed to be occurring in fibres which were undergoing complete degeneration distally. (This could be established with certainty in only some fibres but there was circumstantial evidence for it in others.) A fibre undergoing complete degeneration in its distal part would not, of course, contribute to the muscle action potentials we recorded, and any paranodal demyelination in the proximal part of that fibre would be irrelevant to the motor velocity changes that were found.

A further point which must be taken into consideration is the absence of dispersion of the muscle response. If the paranodal changes were themselves contributing to the reduction in velocity, one would expect dispersion of the muscle response, or at least a lower amplitude response to proximal stimulation than to distal stimulation (Catton, Harrison, Fullerton, and Kazantzis, 1970). However, these phenomena were not seen during the administration of acrylamide, although they were clearly present during regeneration.

These are strong reasons for believing that the progressive fall in maximal conduction velocity during the administration of acrylamide is unrelated to paranodal demyelination, but is due to a selective effect of the toxin on large-diameter fibres; this would result in their becoming inexcitable at a time when conduction could still occur normally in fibres of smaller diameter.

Before accepting this explanation it may well be asked what is the normal range of conduction velocity of the individual motor fibres of a muscle nerve? The results of Eccles, Phillips, and Chien-Ping (1968) indicate that in the nerve to extensor digitorum communis of the baboon, the velocity of individual motor fibres supplying the extrafusal muscle fibres can vary from $49 \mathrm{~m} / \mathrm{sec}$ to $84 \mathrm{~m} / \mathrm{sec}$. We have no comparable physiological data, but from the distribution of fibre diameters found by Wray (1969) in the nerve to abductor pollicis brevis, it seems likely that the slowest alpha motor fibres have a velocity approximately $55 \%$ of that of the fastest.

In the animals studied for long periods after acrylamide had been stopped, recovery of conduction velocity of both motor and sensory fibres was seen. In some cases maximal velocity returned to more than $90 \%$ of its initial value, but in others recovery to only $70 \%$ was seen. This difference may depend upon the length of nerve which had degenerated. If the degeneration had been limited to the distal part, a rapid return to normal would be expected in the proximal part of the nerve once regeneration had occurred (Cragg and Thomas, 1961). If, however, degeneration had spread proximally to involve the region over which conduction velocity was measured, then the velocity might be permanently reduced, as it is in the distal part of a sutured nerve in man (Hodes, Larrabee, and German, 1948; Struppler and Huckauf, 1962). It would be interesting to compare our figures for velocity after acrylamide neuropathy with comparable data for recovering nerves after crush or suture in the baboon. No such figures are available at the present time, but a long-term study of the effects of nerve crush in the baboon has recently been set up, which will be the subject of a separate report.

This work was carried out with a grant from the Medical Research Council which is gratefully acknowledged.

\section{REFERENCES}

Catton, M. J., Harrison, M. J. G., Fullerton, Pamela M., and Kazantzis, G. (1970). Subclinical neuropathy in lead workers. Brit. med. J., 2, 80-82.

Cragg, B. G., and Thomas, P. K. (1961). Changes in conduction velocity and fibre size proximal to peripheral nerve lesions. J. Physiol. (Lond.), 157, 315-327

Eccles, R. M., Phillips, C. G., and Chien Ping, W. (1968). Motor innervation, motor unit organization and afferent innervation of $\mathrm{m}$. extensor digitorum communis of the baboon's forearm. J. Physiol. (Lond.), 198, 179-192.

Fullerton, Pamela M. (1969). Electrophysiological and histological observations on peripheral nerves in acrylamide poisoning in man. J. Neurol. Neurosurg. Psychiat., 32, 186-192.

Fullerton, Pamela M., and Barnes, J. M. (1966). Peripheral neuropathy in rats produced by acrylamide. Brit.J. industr. Med., 23, 210-221.

Gamstorp, I. (1963). Normal conduction velocity of ulnar, median and peroneal nerves in infancy, childhood and adolescence. Acta Pediat., Suppl. 146, 68-76.

Garland, T. O., and Patterson, M. W. H. (1967). Six cases of acrylamide poisoning. Brit. med. J., 4, 134-138.

Gasser, H. S. (1931). Nerve activity as modified by temperature changes. Amer. J. Physiol., 97, 254-270.

Hern, J. E. C. (1970). Personal communication.

Hodes, R., Larrabee, M G., and German, W. (1948). The human electromyogram in response to nerve stimulation and the conduction velocity of motor axons. Studies on normal and on injured peripheral nerves. Arch. Neurol. Psychiat. (Chic.), 60, 340-365.

Hopkins, A. P. (1968). Experimental Neuropathy in the Baboon. M.D. Thesis, University of London.

Hopkins, A. P. (1971). The effect of acrylamide on the peripheral nervous system of the baboon. J. Neurol. Neurosurg. Psychiat., 33, 805-816.

McLeod, J. G., and Wray, Shirley H. (1967). Conduction velocity and fibre diameter of the median and ulnar nerves of the baboon. J. Neurol. Neurosurg. Psychiat., 30, 240-247.

Oxnard, C. E., and Smith, W. T. (1966). Neurological degeneration and reduced serum vitamin $B_{12}$-levels in captive monkeys. Nature (Lond.), 210, 507-509. 
Paintal, A. S. (1965). Effects of temperature on conduction in single vagal and saphenous myelinated nerve fibres of the cat. J. Physiol. (Lond.), 180, 20-49.

Struppler, A., and Huckauf, H. (1962). Propagation velocity in regenerated motor nerve fibres. Eleciroenceph. clin. Neurophysiol., Suppl. 22, 58-60.
Thomas, J. E., and Lambert, E. H. (1960). Ulnar nerve conduction velocity and $\mathrm{H}$-reflex in infants and children. J. app. Physiol., 15, 1-9.

Wray, Shirley H. (1969). Innervation ratios for large and small limb muscles in the baboon. J. comp. Neurol. 137, 227-250. 